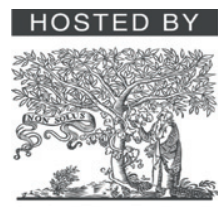

Short communication

\title{
Beeping ICD device: Case report
}

\author{
Hatice S. Kemal ${ }^{\mathrm{a}, *}$, Evrim Şimşek $^{\mathrm{b}}$, Elif İlkay Yuce ${ }^{\mathrm{b}}$, Tahir Yagdı ${ }^{\mathrm{c}}$, Cemil Gurgun $^{\mathrm{b}}$, Mustafa Akın $^{\mathrm{b}}$ \\ a Near East University Hospital, Department of Cardiology, Nicosia, Cyprus \\ b Ege University Hospital, Department of Cardiology, Izmir, Turkey \\ c Ege University Hospital, Department of Cardiovascular Surgery, İmir, Turkey
}

\section{A R T I C L E I N F O}

\section{Article history:}

Received 19 October 2015

Received in revised form 10 November 2015

Accepted 10 November 2015

Available online 18 November 2015

\section{Keywords:}

Pacemaker

Perforation

Right ventricle

\begin{abstract}
A B S T R A C T
A 56-year-old man with history of coronary bypass 6 years ago and ICD implantation 5 months ago was admitted to hospital after hearing a beeping from the ICD. On chest x-ray, the tip of the lead had migrated out of the heart silhouette. Percutaneous lead extraction was performed under close monitoring and fully equipped for pericardiosynthesis and resuscitation with on standby surgical backup. Although right ventricle perforation is a rare complication of pacemaker implants, regardless of the lead fixation mechanism, the possibility of perforation should always be considered.

(C) 2015 The Society of Cardiovascular Academy. Production and hosting by Elsevier B.V. All rights reserved. This is an open access article under the CC BY-NC-ND license (http://creativecommons.org/licenses/by-nc-nd/4.0/).
\end{abstract}

\section{Introduction}

The expanding indications for cardiac pacemaker (PM) and implantable cardioverter defibrillator (ICD) therapy have led to a substantial increase in device implant for the last years. Lead perforation of the right ventricle (RV) is a rare and potentially lethal complication that may occur during, shortly or late after implant. ${ }^{1-3}$

\section{Case report}

We present a 56-year-old man with history of coronary bypass 6 years ago. The patient had ICD (Maximo II VR, Medtronic Inc. Minneapolis, USA) with dual-coil active fixation lead with DF-4 terminal pins (Sprint Quattro, Medtronic Inc. Minneapolis, USA) implant 5 months ago for secondary prevention of sudden cardiac arrest. The patient was admitted to hospital after hearing a beeping from the ICD. Device interrogation showed a decrease in sensed $\mathrm{R}$ wave amplitude to $0.4 \mathrm{mV}$ also RV pacing lead impedance decreased to $494 \Omega$ from $780 \Omega$ and pacing threshold increased to $5 \mathrm{~V}$ at $0.40 \mathrm{~ms}$ pulse width. There was also a lead integrity warning. The decline in lead impedance was suggestive of insulation defect, whereas the decrease in $\mathrm{R}$ wave sense and increase in pacing threshold was suggestive of a lead fracture. The chest x-ray demonstrated that the tip of the lead had migrated out of the heart silhouette. Computed tomographic (CT) scan confirmed the

\footnotetext{
* Corresponding author. Tel.: + 3579005338478506.

E-mail addresses: kemal.hatice@hotmail.com (H.S. Kemal), drevrimsimsek@gmail.com (E. Simșek), i.elif9@hotmail.com (E.İ. Yuce), tahir.yagdi@gmail.com (T. Yagdı), cemil.gurgun@gmail.com (C. Gurgun), mustafa.akin@ege.edu.tr (M. Akın).

Peer review under responsibility of The Society of Cardiovascular Academy.
}

perforation and minimal pneumothorax (Fig. 1A-B). Transthoracic echocardiography revealed no pericardial effusion. Percutaneous lead extraction was performed in the coronary angiography room under close monitoring and fully equipped for pericardiosynthesis and resuscitation with on standby surgical backup. Soft stylet inserted in the lead and active fixation tip was retracted, then the lead was removed manually with simple traction through the left subclavian vein under fluoroscopic guidance. No complications occurred after removal. After a week, a new passive fixation ICD lead was implanted and post implantation chest $\mathrm{X}$-ray and CT scan confirmed that the pacemaker lead was in RV apex. (Fig. 1C-D).

\section{Discussion}

Pacemaker lead perforation is a rare complication of pacemaker implantation, ranging from $0.1 \%$ to $0.8 \%$ in PM ventricular leads and 0.6-5.2\% in ICD leads. ${ }^{1}$ Acute lead perforation occurring during or soon after the procedure usually manifests as cardiac tamponade due to acute pericardial effusion, while late cardiac perforation can be asymptomatic. The late presentation is a less recognized complication but can have serious consequences if unrecognized. Lead perforation may be attributed to a combination of factors including patient characteristics, lead tip position, use of oral steroids, implant technique and the design characteristics of the lead. ${ }^{4}$ Patients can admit with different symptoms; pericardial pain, dyspnea, syncope, ICD shock, poor sensing, pericardial effusion, hemothorax or like in our patient ICD alarm. ICDs have inbuilt alarm systems to notify patients of the need to seek assistance.

The data on how to manage delayed RV-lead perforation, whether to extract the lead or not, and if so, whether to extract perforating leads percutaneously or surgically, are very limited. ${ }^{5,6}$ There are reported cases of tamponade occurring with late RV perforation treated with 

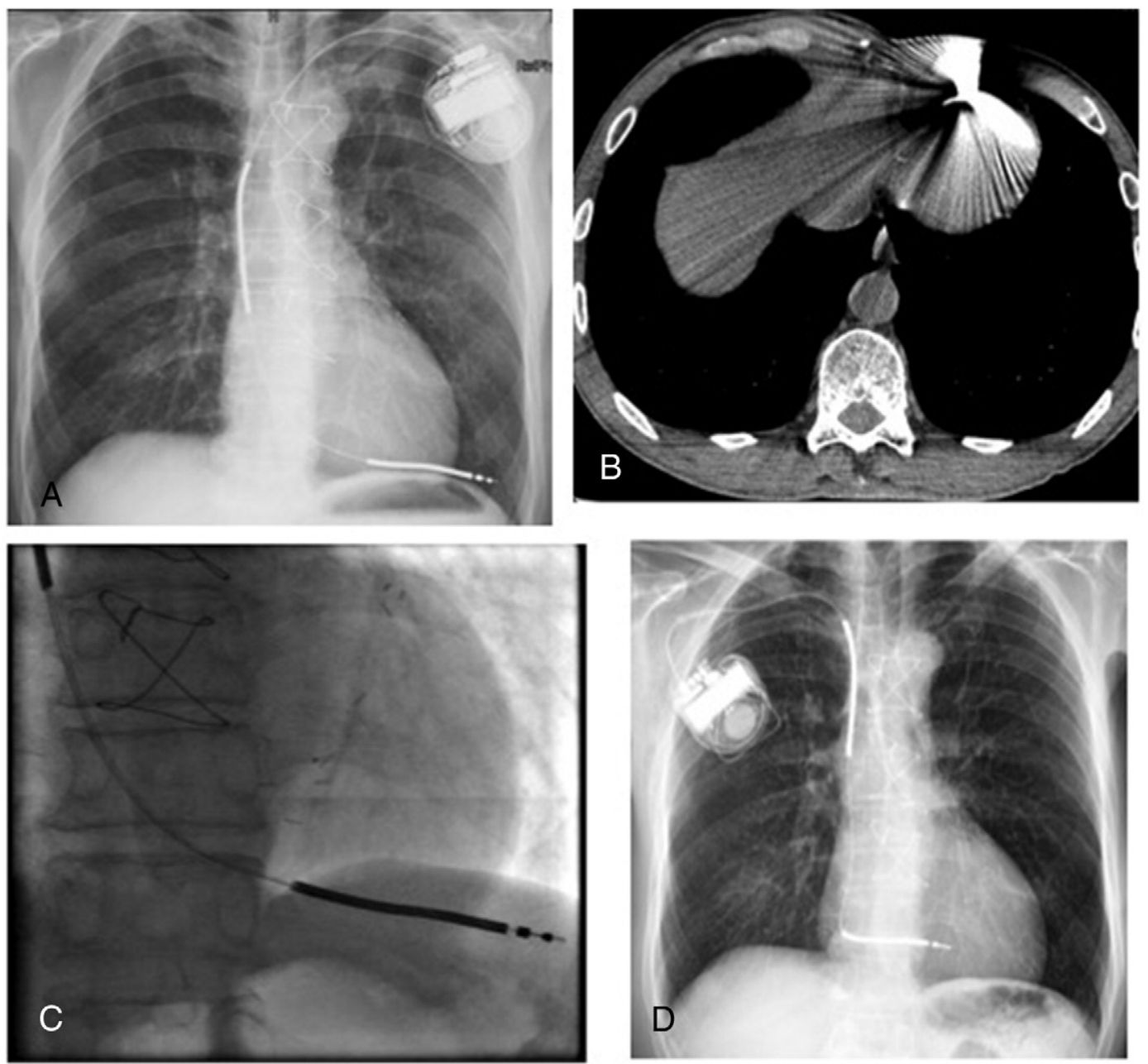

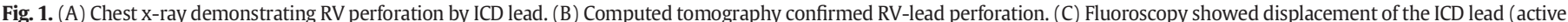

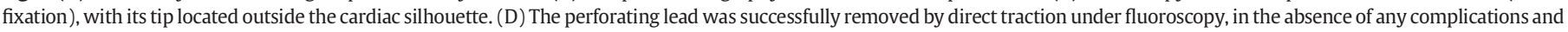
a new lead was placed.

percutaneous lead extraction by simple traction, but this complication is rare. ${ }^{3,7}$ Not removing dysfunctional lead in a patient without infective endocarditis can sometimes be an option, however, veins can only accommodate a limited number of leads due to space constraints, and also it is more difficult to extract old leads after more time in the body.

In our case no complication accords after simple direct manual traction of the RV lead under fluoroscopic guidance. It may be possible that withdrawing the perforating lead did not cause significant bleeding in the pericardium because of the myocardium self-sealing properties and the pericardium might have been stiff due to previous cardiac operation. However, because of the possibility of acute life-threatening pericardial bleeding, the procedure should be carefully scheduled and a surgical backup should be mandatory.

\section{Conclusion}

As pacemaker lead perforation can be during or early after implantation, it can occur late. In most patients, percutaneous lead extraction by simple traction is a safe and effective management approach that may be performed in the electrophysiology room with surgical backup.

\section{References}

1. Khan MN, Joseph G, Khaykin Y, et al. Delayed lead perforation: a disturbing trend. Pacing Clin Electrophysiol 2005;28:251-253.

2. Alter P. Waldhans S, Plachta $E$, et al. Complications of implantable cardioverter defibrillator therapy in 440 consecutive patients. Pacing Clin Electrophysiol 2005;28: 926-932.

3. Laborderie J, Barandon L, Ploux S, et al. Management of subacute and delayed right ventricular perforation with a pacing or an implantable cardioverter-defibrillator lead. Am J Cardiol 2008;102:1352-1355.

4. Danik SB, Mansour M, Heist EK, et al. Timing of delayed perforation with the St. Jude Riata lead: a single-center experience and a review of the literature. Heart Rhythm 2008;5:1667-1672.

5. Wilkoff BL, Love CJ, Byrd CL, et al. Transvenous lead extraction: Heart Rhythm Society expert consensus on facilities, training, indications, and patient management: this document was endorsed by the American Heart Association (AHA). Heart Rhythm 2009;6: 1085-1104

6. Refaat MM, Hashash JG, Shalaby AA. Late perforation by cardiac implantable electronic device leads: clinical presentation, diagnostic clues, and management. Clin Cardiol 2010;33:466-475

7. Migliore F, Zorzi A, Bertaglia E, et al. Incidence, management, and prevention of right ventricular perforation by pacemaker and implantable cardioverter defibrillator leads. Pacing Clin Electrophysiol 2014;37:1602-1609. 